\title{
Orbital floor fractures - short- and intermediate-term complications depending on treatment procedures
}

\author{
Henrik Holtmann ${ }^{1 *}$, Hatice Eren² ${ }^{2}$ Karoline Sander ${ }^{1}$, Norbert R. Kübler ${ }^{1}$ and Jörg Handschel ${ }^{1}$
}

\begin{abstract}
Background: Many reconstruction materials for orbital floor fractures have been described in the past including autologous bone transplants, resorbable polymers and titan meshes. So far evidence is missing which material is used successfully regarding indication and particular size of defect. Therefore the aim of this study was to evaluate which reconstruction technique produces best clinical outcome and least complications associated with indication.

Methods: Retrospectively, surgical and ophthalmological data plus CT scans from a collective of 775 patients between 2005 and 2012 were analyzed. Furthermore included patients were sounded on satisfaction and potential problems postoperatively.

Results: Overall 593 patients offered full pre- and postoperative short-time data appropriate to inclusion criteria of these $507(85,5 \%)$ underwent primary surgical treatment. Smallest average defect size was found in cases with no indication for surgical treatment $\left(81 \mathrm{~mm}^{2}\right)$, largest in cases indicating titanium mesh reconstruction $\left(601.5 \mathrm{~mm}^{2}\right)$. In 15 cases exact fragment reposition was possible without insertion of alloplastic material. Best clinical results obtained reconstruction using polydioxanone foil (PDS). $0.15 \mathrm{~mm}$ PDS-foil: 444 patients, reduced diplopia pre to postoperative 16 to $6 \%(p<0.01)$, ex- and enophthalmus $<2 \%$ after surgery. $0.25 \mathrm{~mm}$ PDS-foil: 26 patients, reduced diplopia from pre- to postoperative 34,6 to $3,8 \%(p<0.01)$, postoperative exophthalmus rate was higher than preoperative (3,8 to 7,7\%). In comparison to reconstruction with PDS-foil a higher percentage of patients reconstructed with titanium meshes $(n=22)$ revealed no significant reduction of diplopia $(45,5$ to $31,8 \% ; p=0.07)$. Furthermore 63 of all included patients agreed to complete a questionnaire on intermediate-term postoperative symptoms and surgical contentedness. Remarkably $50 \%$ of the patients reconstructed with titanium meshes indicated foreign body sensations and cold feeling in the long-term.
\end{abstract}

Conclusions: Short- and intermediate-term results of clinical outcome in our patients with surgical treated orbital floor fractures (i.e. diplopia, en- or exophthalmus) reveal that thin resorbable foils, particularly $0.15 \mathrm{~mm}$ diameter PDS-foil seem to generate best results referring to orbital floor defects with a size of 250 to $300 \mathrm{~mm}^{2}$.

Trial registration: Study number 4222, year 2013, ethics committee of the medical faculty of the Heinrich Heine university of Duesseldorf.

Keywords: Orbital floor fracture, Surgical reconstruction, Titanium mesh, Resorbable polydioxanone foil, Internal orbital reconstruction

\footnotetext{
* Correspondence: Henrik.Holtmann@med.uni-duesseldorf.de

${ }^{1}$ Department of Oral and Maxillofacial Surgery, Plastic Surgery of the Face,

University Hospital of Duesseldorf, Moorenstr. 5, D-40225 Duesseldorf,

Germany

Full list of author information is available at the end of the article
} 


\section{Background}

In the past years a lot of reconstruction principles and materials have been described for orbital floor fractures. Regarding the management of orbital floor fractures there is still no profound reliable consensus regarding the indication for surgery, best time of surgery and the risk for late enopthalmus. Often the decision for surgery is based on individual and local traditions all over the world [1] and first treatment algorithms are established [2] but not proceeded in the whole world.

Concerning the materials that are used to reconstruct the fractured orbital floor the trend is leaving autogenous (bone) grafts to well tolerate alloplastic materials emerged in the past few years. But even in the field of reconstruction materials there is no reliable consensus which material is the best to use. Often the decision for a certain material depends on surgeon preference, experience and comfort [3].

Mok et al. [4] performed a review of the literature that gained to find out the optimal material for reconstruction defining the following required characteristics: resorbable, osteoconductive, resistant to infection, minimal reactive, no capsule formation, half-life which would allow significant bony ingrowth, cheap and readily available. Summarizing these requirements, the article concludes that no material that is actually being used unites all these attributes. Therefore Avashia et al. developed a decision-making algorithm for orbital floor reconstruction materials in 2012 by reviewing all available literature [5]. Even in this retrospective analysis the authors bewail a lot of flaws in the study designs of the included literature so that no closing statement can be given which material should be used preferrably for orbital floor fracture reconstruction. Strong EB et al. confirm this statement in a current study [6]. Leaving these definition attempts actual published literature shows that especially alloplastic materials are mainly used to reconstruct the destroyed orbital floor due to their current availability, clinical and operative cost and their overall ability for well-tolerance [3].

One of these important alloplastic materials is titanium. In 2003 Ellis $3^{\text {rd }}$ and Tan were able to show that titanium meshes are more accurate to reconstruct the orbital floor than bone grafts [7]. Kirby et al. confirmed these findings in a retrospective study with 317 adult patients comparing patients who had been reconstructed with bone grafts to patients reconstructed with titanmesh and/or polyethylene [8]. Even though chronic enophthalmus (persisting more than 4 weeks) was significantly reduced in those patients with alloplastic reconstruction, (23 to $14 \%$ ) diplopia was increased (17 to $14 \%$ ) in comparison to patients reconstructed with bone grafts. A new publication with 144 patients reconstructed with preformed titanium-meshes showed low postoperative rates of enophthalmus $(3,8 \%)$ and diplopia $(2,2 \%)[9]$.

In 2004 Ellis $3^{\text {rd }}$ and Messo additionally estimated that titanium meshes and porous polyethylene are more compatible to reconstruct orbital floor fractures than for example silicone or Teflon ${ }^{\circ}$ and even better than resorbable alloplastic materials like polydioxanone (PDS) membranes [10]. Polydioxanone maintains up to 12 month in the orbital soft tissue until full degradation, sometimes degradation seems to be incomplete and granulomas occur more often due to a sterile inflammatory cellular reaction lining the degrading polymer fragments. On the other hand a vigorous fibrotic reaction can also be seen in patients with titanium mesh implants [11]. And furthermore an increased rate of infection, extrusion, implant migration and residual diplopia has also been reported for patients reconstructed with titanium meshes [12]. Kontio et al. used pre- and postoperative CT- and MRI-scans which showed unsatisfactory reconstructed orbital shapes after reconstruction with polydioxanone membrane (thickness $0.25 \mathrm{~mm}$ or $1 \mathrm{~mm}$ ), revealing not adequately restored orbital volume and thick soft tissue scar formation [13]. Unfortunately this study only consisted of 16 patients and defect size was not mentioned. Baumann et al. also examined polydioxanone $(0.25$ or $0.5 \mathrm{~mm}$ thick) reconstructed orbital floor fractures and concluded that polydioxanone should only be used in fractures up to $2.5 \mathrm{~cm}^{2}$. Patients with larger defects had an increased risk of developing enophthalmus due to its missing stiffness and stability to hold back the orbital soft tissue. Evaluationg radiographs they also discovered that newly build bone did not occur in the defects after resorption of polydioxanone [14].

Gierloff et al. extended the indication for using polydioxanone foils. Inter alia 47 patients with defects $>$ $2.0 \mathrm{~cm}^{2}$ were treated using foils with a thickness of $0.25 \mathrm{~mm}$ and revealing a reduction preoperative to 6 month postoperative of eye mobility disorders from 31 to $5 \%$ and enophthalmus from 5 to $2 \%$ [15]. Gerressen et al. reinforced these findings in 21 patients evaluating postoperative CT-scans. They described the usefulness of polydioxanone foil $(0.25 \mathrm{~mm})$ or ethisorb patch reconstructing the orbital geometry even in cases with extensive fractures (median: $4.32 \mathrm{~cm}^{2}$ ) comparing the results to the healthy side [16]. A significant reduction of diplopia from $57 \%$ (preoperative) to $19 \%$ postoperative (median: 27.4 month postoperative) was shown.

A current study enrolling 78 patients could even show no relevant functional difference using neither resorbable nor titanium-dynamic mesh plates concerning defect size and reduction of enophthalmus, extraocular movement disorders and diplopia [17]. 
Although a lot of approaches were made to define whether titanium meshes are more effective than absorbable materials to reconstruct the fractured orbital floor (particularly polydioxanone sheets) as seen above this question remains unacknowledged up to now due to fact that no material has only advantages. Even the question on which material is best choice for which size of defect cannot be answered properly regarding the present international literature so far. Therefore the purpose of this study is to evaluate alloplastic materials (polydioxanone foil with a thickness of $0.15 \mathrm{~mm}$ or $0.25 \mathrm{~mm}$ and titanium meshes) currently used in a large number of patients specifying which material should be used for which indication in purpose of a successful reconstruction.

\section{Methods}

\section{Study design and methods}

We performed a retrospective study for a collective of 775 patients with orbital floor fractures (isolated or combined to other midfacial fractures) admitted to and treated in the clinic of oral, maxillofacial and plastic facial surgery at the university of Duesseldorf, Germany in the years 2005-2012.

Data basis was all clinical data of the patients including preoperative CT-scans, preoperative ophthalmological consultations and ophthalmological consultations 2 weeks postoperative. Target parameters and data inclusion criteria were pre- and postoperative diplopia, extraocular movement disorders, exophthalmus, enophthalmus and primary surgical treatment.

Size of orbital floor defect was calculated analog to Ellis $3^{\text {rd }}$ and Tan 2003 by analyzing coronal slices of CTscans of the orbital floor [7]. To get the correct defect size the number of slices was counted in which one could see the defect. Afterwards this number was multiplicated with the thickness of the slices and the defect size mediolateral (Fig. 1).

Additionally for patients between 2010 and 2012 with fully documented pre- and postoperative data a questionnaire of contentedness was performed (collective height: 83 patients; attendance: 63 patients) at minimum 8 month and at maximum 36 month after surgical intervention. This questionnaire aimed to get further subjective information of these patients concerning aesthetic aspects of the infraorbital pit, function (extraocular movement, diplopia, hypesthesia, lower eyelid function) and general treatment/results by using free questions, multiple choice and visual analogue scale in alteration.

\section{Statistics}

Data analysis and presentation was performed descriptively in SPSS vers. 22 (IBM Corporation, Armonk, NY,

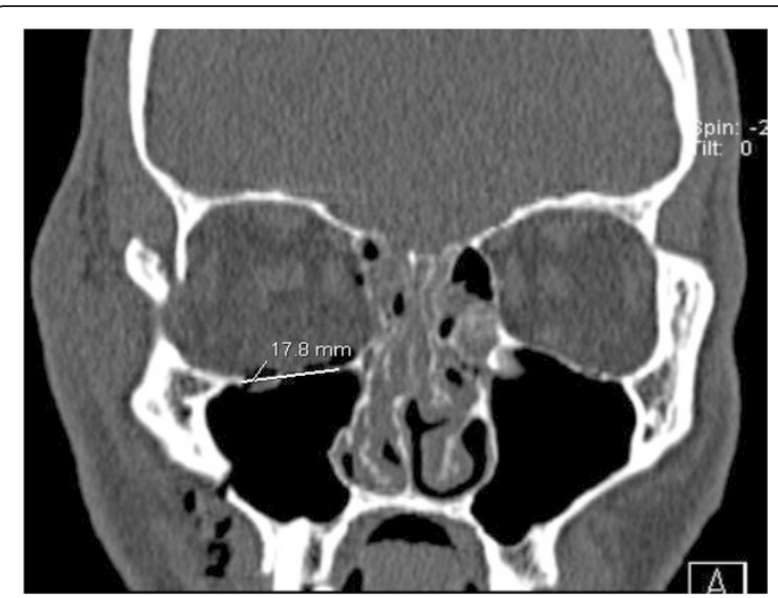

Fig. 1 Coronal slice of a native $C T$-scan of the midfacial area for the measurement of orbital floor defect sizes. Shown is a zygomatic bone fracture on the right side involving the lateroorbital column, the orbital floor and the anterior maxillary sinus wall

USA) and MS Excel (Microsoft Corporation, Redmond, WA, USA) and controlled by a statistician.

\section{Results \\ Collective}

An over all collective of 775 patients in the years 2005 up to 2012 was examined (541 [69,8 \%] male and 243 [30,2\%] female patients). Median age was 44 (mean value 46 years; minimum 3 years, maximum 94 years [standard deviation 20,87]). In 593 patients full pre- and postoperative data appropriate to inclusion criteria was available. $507(85,5 \%)$ of these patients underwent primary surgical treatment, 86 had no surgical indication, refused surgical treatment or had contraindications against surgery (Fig. 2). The smallest average defect one could find occurred in cases with no indication to a surgical procedure $\left(81 \mathrm{~mm}^{2}\right)$, the largest in cases with titanium mesh reconstruction $\left(601,5 \mathrm{~mm}^{2}\right)$. Time for surgical intervention ranged from average 55 min for exact reposition without need of alloplastic material insertion, $77 \mathrm{~min}$ using $0.15 \mathrm{~mm}$ diameter PDS-foil, $95 \mathrm{~min}$ applying titanium mesh up to $105 \mathrm{~min}$ inserting $0.25 \mathrm{~mm}$ diameter PDS-foil.

\section{Collective with no surgical indication}

In cases with no surgical indication diplopia occurred preoperative in 10 cases with a reduction to one case 1 weeks postoperative $(p<0.01)$. Presurgical exophthalmus occurred in this collective in 2 cases, postoperative only in 1 case (not significant [n.s.]). No ex- or enophthalmus was present in any pre- and postoperative case (Table 1). Minimum defect size was $2,3 \mathrm{~mm}^{2}$, maximum was $515 \mathrm{~mm}^{2}$. 


\section{examinated collective}
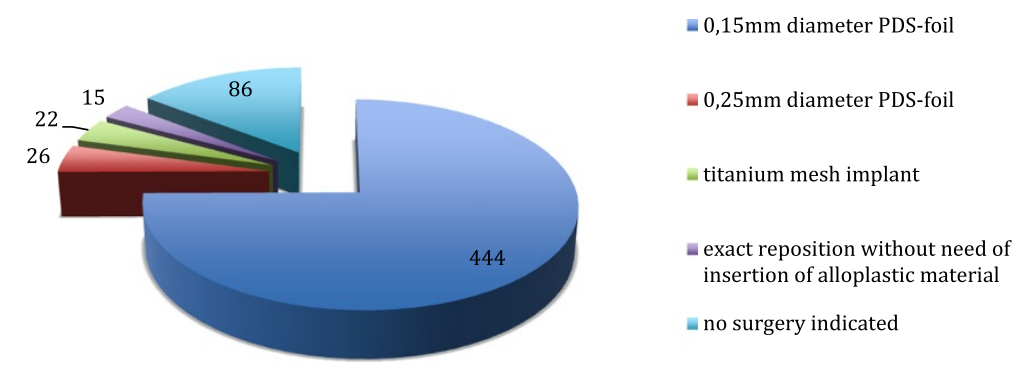

Fig. 2 Examinated patients' collective ( $n=593$ patients)

\section{Cases with possible exact reposition and no need to insert alloplastic material}

Preoperative diplopia occurred in one case, postoperatively no diplopia occurred (n.s.). No pre- or postoperative exophthalmus or enophthalmus was observed. Minimum defect size was $49 \mathrm{~mm}^{2}$, maximum defect size treated in this group was $450 \mathrm{~mm}^{2}$ (Table 1).

\section{Reconstruction with 0,15 $\mathrm{mm}$ diameter PDS-foil}

Whereas $16 \%$ (average) of the patients presented preoperative diplopia, only $4,9 \%$ showed this postoperative which means a significant reduction $(p<0.01)$. Ex- and enophthalmus was only mentioned in a very low number of patients in this group. Consequentially no significant reduction from pre- to postoperative could be evaluated. Minimum defect size was $7,2 \mathrm{~mm}^{2}$, maximum defect size treated in this group was $370,8 \mathrm{~mm}^{2}$ (Table 1 ).

\section{Reconstruction with $\mathbf{0 , 2 5} \mathrm{mm}$ diameter PDS-foil}

In comparison to the reconstruction with the thinner diameter foil a significant reduction of diplopia preto postoperative $(34,6$ to $3,8 \% ; p<0.01)$ could be obtained. Pre- and postoperative data concerning exand enopthalmus were corresponding to the reconstructions using the $0.15 \mathrm{~mm}$ PDS-foil. Minimum defect size was $100 \mathrm{~mm}^{2}$, maximum defect size treated in this group was $825 \mathrm{~mm}^{2}$ (Table 1).

\section{Reconstruction with titanium mesh}

In comparison to reconstruction with PDS-foil a higher percentage of patients of this collective had a preoperative diplopia $(45,5 \%)$. There was no significant difference in the potential reduction compared to the postoperative stadium $(31,8 \% ; p=0,07)$. An enophthalmus was diagnosed preoperatively in $13,6 \%$ of the cases presumably due to the average size of defects and was reduced in each case following surgery. Exophthalmus was no problem neither pre- nor postoperative. However the low number of patients in this group leads to limitations in validity of the data. Minimum defect size was $100.8 \mathrm{~mm}^{2}$, maximum defect size treated in this group was $1004 \mathrm{~mm}^{2}$ (Table 1).

\section{Patient contentedness}

83 Patients in the years 2010 to 2012 additionally received a written questionnaire about postoperative symptoms and surgical contentedness. The questionnaires were handed out at a minimum of eight and at a maximum 36 months after initial trauma, to ensure documentation of potential long-term effects after injury or surgical intervention. 63 agreed in and answered this questionnaire. In 12 cases no surgical treatment was indicated, in two cases exact reposition of the fragments was possible equaling no insertion of alloplastic material. In 43 cases a $0.15 \mathrm{~mm}$ diameter foil was applied, two patients received a $0.25 \mathrm{~mm}$ diameter foil and four a titanium mesh. The impairment results are mentioned

Table 1 Treatment depending symptoms (percentages in relation to complete collective)

\begin{tabular}{|c|c|c|c|c|c|c|c|}
\hline \multirow[t]{2}{*}{ Treatment } & \multirow{2}{*}{$\begin{array}{l}\text { median defect } \\
\text { size }\left(\mathrm{mm}^{2}\right)\end{array}$} & \multicolumn{2}{|l|}{ Diplopia } & \multicolumn{2}{|l|}{ Exopthalmus } & \multicolumn{2}{|c|}{ Enophthalmus } \\
\hline & & Pre-surgery & Post-surgery & Pre-surgery & Post-surgery & Pre-surgery & Post-surgery \\
\hline No surgery indicated & 81,0 & $10(11,6 \%)$ & $1(1,2 \%)$ & $2(2,3 \%)$ & $1(1,2 \%)$ & $0(0 \%)$ & $0(0 \%)$ \\
\hline $\begin{array}{l}\text { Exact reposition without need } \\
\text { of insertion of alloplastic material }\end{array}$ & 142,8 & $1(6,7 \%)$ & $0(0 \%)$ & $0(0 \%)$ & $0(0 \%)$ & $0(0 \%)$ & $0(0 \%)$ \\
\hline 0,15 mm diameter PDS-foil & 267,3 & $74(16 \%)$ & $21(4,9 \%)$ & $11(2,5)$ & $8(1,8 \%)$ & $4(0,9 \%)$ & $6(1,4 \%)$ \\
\hline 0,25 mm diameter PDS-foil & 437,3 & $9(34,6 \%)$ & $1(3,8 \%)$ & $1(3,8 \%)$ & $2(7,7 \%)$ & $1(3,8 \%)$ & $1(3,8 \%)$ \\
\hline Titanium mesh implant & 601,5 & $10(45,5 \%)$ & $7(31,8 \%)$ & $0(0 \%)$ & $0(0 \%)$ & $3(13,6 \%)$ & $0(0 \%)$ \\
\hline
\end{tabular}


in Table 2. They mainly correlate with the short-term results. Moreover $50 \%$ of the patients reconstructed with titanium meshes indicate foreign body sensations and cold feeling during changes in weather in the area of operation. Again it is to be mentioned that the validity of these results is limited due to the low number of patients in this collective.

\section{Discussion}

Regarding the current data of this study the PDS-foil seems to be the adequate material to reconstruct orbital floor fractures with average sizes of $267 \mathrm{~mm}^{2}(0.15 \mathrm{~mm}$ diameter foil) up to $437 \mathrm{~mm}^{2}$ in average $(0.25 \mathrm{~mm}$ diameter foil). In single cases even $0.25 \mathrm{~mm}$ diameter foil was able to reconstruct defects up to $825 \mathrm{~mm}^{2}$, probably leading to an overlapping indication in terms of patients reconstructed with titanium meshes and their average defect size of $602 \mathrm{~mm}^{2}$. The $0.15 \mathrm{~mm}$ diameter foil is able to reduce pre- to postoperative diplopia from 16 to $4,9 \%$ along with a low tolerable rate of postoperative exand enophthalmus $(1,8 \% / 1,4 \%)$. Reconstructed patients with $0.25 \mathrm{~mm}$ diameter foil reveal similar results concerning pre- to postoperative reduction of diplopia. Long-term data of the patients who completed the questionnaire confirms these results even though this group was slightly smaller. Moreover reconstruction with $0.15 \mathrm{~mm}$ diameter PDS-foil overall requires the least time for surgical intervention being compared to reconstructions applying $0.25 \mathrm{~mm}$ diameter PDS-foil or titanium mesh. Our data approve the studies of Gierloff et al. and Gerressen et al. $[15,16]$. However, our collective of patients with short- and long-term results is distinctively bigger especially concerning reconstructed cases using 0.15 and $0.25 \mathrm{~mm}$ diameter PDS foil. Thus our data enhances the long-term clinical results of Gerressen et. al. regarding reconstruction of greater defects (average $432 \mathrm{~mm}^{2}$ by Gerressen et al. [16], average $437 \mathrm{~mm}^{2}$ in our study for reconstruction with $0.25 \mathrm{~mm}$ diameter PDS-foil). Although our group of titanium-mesh reconstructed patients is much smaller than the one reconstructed with PDS-foil its results are remarkable: insufficient short-term reduction of diplopia and long-term foreign-body feeling. Whereas a low rate of enophthalmus which was found earlier by Rosado and de Vicente et al. was also apparent in our study, we were not able to confirm the superior reduction of diplopia for titanium meshes [9]. Our findings are contrary to a present study of Baek et al. who reported resorbable and non-resorbable implants to be equally effective concerning postoperative risks and functions [17]. Ultimately the PDS-foil seems to fit for a great range of orbital floor fractures but not for every case. One the one hand small defects perhaps do not need any implant or even a surgical intervention, which reveals our results for the groups without any intervention and exact reposition of fragments without alloplastic implant. On the other hand defects with a wide range do not reveal perhaps enough bracing for the foil and the foil for the orbital tissue lying on the foil. For these cases prefabricated meshes or even individually bent titanium meshes sometimes with required navigated insertion are necessary with reasonable postoperative symptoms [18].

Even though the number of patients in the surgical treatment groups of our study is with no doubt differing determining limited significance, our results remain remarkably and may help to establish profound treatment algorithms in future.

\section{Conclusions}

In conclusion we suggest that reconstruction of orbital floor fractures with PDS-foil taking indication and defect size (median: $437 \mathrm{~mm}^{2}$ for $0.25 \mathrm{~mm}$ diameter PDS-foil) into account comes along with a low and acceptable rate of postoperative diplopia, ex- and enophthalmus in the majority of cases. Particularly the $0.15 \mathrm{~mm}$ diameter PDS-foil seems to generate the best clinical results including median orbital floor defects with a size of 250 to $300 \mathrm{~mm}^{2}$ resulting in the lowest postoperative rate of diplopia and en- and/or exophthalmus.

The indication for a reconstruction with titanium meshes (even cases with individually bent meshes with or without navigated insertion) should be reduced to cases of extensive fractures keeping the insufficient reduction of diplopia and the remarkably high percentage of foreign body sensations in mind.

Table 2 Intermediate-term patient impairments

\begin{tabular}{|c|c|c|c|c|c|}
\hline Treatment & Median defect size $\left(\mathrm{mm}^{2}\right)$ & $\begin{array}{l}\text { Foreign body sensation/cold } \\
\text { feeling when weather is } \\
\text { changing ( } \% \text { of collective) }\end{array}$ & $\begin{array}{l}\text { Postoperative } \\
\text { diplopia (n) }\end{array}$ & $\begin{array}{l}\text { Postoperative } \\
\text { exophthalmos (n) }\end{array}$ & $\begin{array}{l}\text { Postoperative } \\
\text { enophthalmus ( } n \text { ) }\end{array}$ \\
\hline No surgigal treatment indicated & 135,64 & $0 \%$ & 0 & 0 & 0 \\
\hline $\begin{array}{l}\text { Exact reposition without need of } \\
\text { insertion of alloplastic material }\end{array}$ & 89,9 & $0 \%$ & 0 & 0 & 0 \\
\hline 0,15 mm diameter PDS-foil & 319,71 & $4,7 \%$ & 1 & 1 & 0 \\
\hline 0,25 mm diameter PDS-foil & 448,8 & $0 \%$ & 0 & 0 & 0 \\
\hline Titanium mesh implant & 481,67 & $50 \%$ & 0 & 0 & 0 \\
\hline
\end{tabular}




\section{Ethics}

This retrospective study has been approved by the ethics committee of the medical faculty of the university of Duesseldorf (study number 4222, year 2013).

\section{Competing interests}

The authors declare that they have no competing interests or extraclinical source of funding that could affect the neutrality of the authors.

\section{Authors' contributions}

H.H. wrote this publication based on the data that have been taken retrospectively. J.H. was the principle investigator of this study. He corrected and approved this manuscript. H.E. collected the data supervised by J.H. She aims to do her doctoral thesis out of this data. N.R.K. and K.S. approved this manuscript. All authors read and approved the final manuscript.

\section{Acknowledgement}

The authors want to thank all non-academic and academic associates of their clinics who collected all the data through all the years. Without their help it wouldn't have been possible to conduct this retrospective study.

\section{Author details}

'Department of Oral and Maxillofacial Surgery, Plastic Surgery of the Face, University Hospital of Duesseldorf, Moorenstr. 5, D-40225 Duesseldorf, Germany. ${ }^{2}$ Department for Oral Surgery, University Hospital of Duesseldorf, Moorenstr. 5, D-40225 Duesseldorf, Germany.

\section{Received: 8 April 2015 Accepted: 18 December 2015}

Published online: 05 January 2016

\section{References}

1. Alinasab B, Ryott M, Stjarne P. Still no reliable consensus in management of blow-out fracture. Injury. 2014;45(1):197-202.

2. Ellis 3rd E, Perez D. An algorithm for the treatment of isolated zygomaticoorbital fractures. J Oral Maxillofac Surg. 2014:72(10):1975-83.

3. Potter JK, Malmquist M, Ellis 3rd E. Biomaterials for reconstruction of the internal orbit. Oral Maxillofac Surg Clin North Am. 2012;24(4):609-27.

4. Mok D, Lessard L, Cordoba C, Harris PG, Nikolis A. A review of materials currently used in orbital floor reconstruction. Can J Plast Surg. 2004;12(3): 134-40.

5. Avashia YJ, Sastry A, Fan KL, Mir HS, Thaller SR. Materials used for reconstruction after orbital floor fracture. J Craniofac Surg. 2012;23(7 Suppl 1):1991-7.

6. Strong EB, Fuller SC, Chahal HS. Computer-aided analysis of orbital volume: a novel technique. Ophthal Plast Reconstr Surg. 2013;29(1):1-5.

7. Ellis 3rd E, Tan $Y$. Assessment of internal orbital reconstructions for pure blowout fractures: cranial bone grafts versus titanium mesh. J Oral Maxillofac Surg. 2003;61(4):442-53.

8. Kirby EJ, Turner JB, Davenport DL, Vasconez HC. Orbital floor fractures: outcomes of reconstruction. Ann Plast Surg. 2011;66(5):508-12.

9. Rosado P, de Vicente JC. Retrospective analysis of 314 orbital fractures. Oral Surg Oral Med Oral Pathol Oral Radiol. 2012;113(2):168-71.

10. Ellis 3rd E, Messo E. Use of nonresorbable alloplastic implants for internal orbital reconstruction. J Oral Maxillofac Surg. 2004;62(7):873-81.

11. Kersey TL, Ng SG, Rosser P, Sloan B, Hart R. Orbital adherence with titanium mesh floor implants: a review of 10 cases. Orbit. 2013;32(1):8-11.

12. Hwang $\mathrm{K}$, You SH. Analysis of facial bone fractures: an 11-year study of 2,094 patients. Indian J Plast Surg. 2010;43(1):42-8.

13. Kontio $\mathrm{R}$, Suuronen $\mathrm{R}$, Salonen $\mathrm{O}$, Paukku $\mathrm{P}$, Konttinen $\mathrm{YT}$, Lindqvist $\mathrm{C}$. Effectiveness of operative treatment of internal orbital wall fracture with polydioxanone implant. Int J Oral Maxillofac Surg. 2001;30(4):278-85.

14. Baumann A, Burggasser G, Gauss N, Ewers R. Orbital floor reconstruction with an alloplastic resorbable polydioxanone sheet. Int J Oral Maxillofac Surg. 2002;31(4):367-73.

15. Gierloff M, Seeck NG, Springer I, Becker S, Kandzia C, Wiltfang J. Orbital floor reconstruction with resorbable polydioxanone implants. J Craniofac Surg. 2012;23(1):161-4.

16. Gerressen M, Gillessen S, Riediger D, Holzle F, Modabber A, Ghassemi A Radiologic and facial morphologic long-term results in treatment of orbital floor fracture with flexible absorbable alloplastic material. J Oral Maxillofac Surg. 2012;70(10):2375-85.

17. Baek WI, Kim HK, Kim WS, Bae TH. Comparison of absorbable mesh plate versus titanium-dynamic mesh plate in reconstruction of blow-out fracture: an analysis of long-term outcomes. Arch Plast Surg. 2014;41(4): 355-61.

18. Essig H, Dressel L, Rana M, Rana M, Kokemueller H, Ruecker M, et al. Precision of posttraumatic primary orbital reconstruction using individually bent titanium mesh with and without navigation: a retrospective study. Head Face Med. 2013;9:18.

\section{Submit your next manuscript to BioMed Central and we will help you at every step:}

- We accept pre-submission inquiries

- Our selector tool helps you to find the most relevant journal

- We provide round the clock customer support

- Convenient online submission

- Thorough peer review

- Inclusion in PubMed and all major indexing services

- Maximum visibility for your research

Submit your manuscript at www.biomedcentral.com/submit
) Biomed Central 